\title{
BMJ Open Changing mindsets about side effects
}

\author{
Kari A Leibowitz (D) , ${ }^{1}$ Lauren C Howe, ${ }^{2}$ Alia J Crum ${ }^{1}$
}

To cite: Leibowitz KA, Howe LC, Crum AJ. Changing mindsets about side effects. BMJ Open 2021;11:e040134. doi:10.1136/ bmjopen-2020-040134

- Prepublication history for this paper is available online. To view these files, please visit the journal online (http://dx.doi. org/10.1136/bmjopen-2020040134).

Received 05 May 2020

Revised 03 November 2020

Accepted 24 November 2020

\section{ABSTRACT}

Given research showing that the very act of communicating side effects can increase their likelihood, how can providers inform patients about side effects while upholding their oath to do no unnecessary harm? An emerging approach provides a potential solution: truthfully describe certain minor side effects as a sign the treatment is active and working in the body. This approach focuses on instilling adaptive mindsets about the meaning of side effects while still keeping patients informed. This article describes existing research suggesting that this approach can be helpful in improving experience and outcomes in treatments for pain, hypertension and allergy. Compared with control groups given a standard, empathetic message about side effects, patients who were informed that side effects are a sign treatment is working were less anxious about side effects and rated them as less threatening and intense. A longitudinal, randomised controlled trial of this approach in patients receiving oral immunotherapy for food allergies found that describing side effects as a sign treatment was working reduced the rate at which patients contacted providers with concerns about side effects and led to greater increases in a biomarker of allergic tolerance from pretreatment to post-treatment (peanut-specific blood lgG4). In unveiling this approach, this article also raises important issues regarding which treatments and symptoms this approach should be applied to. Finally, we outline questions future research should address to further understand and leverage this approach.

\section{CHANGING MINDSETS ABOUT SIDE EFFECTS}

Describing certain minor side effects as a sign that treatment is active and working can improve treatment experience while keeping patients fully informed about potential side effects.

Providers are ethically obligated to inform patients about possible treatment side effects. Yet the very act of communicating side effects can increase their likelihood. ${ }^{1-4}$ For example, compared with men who were not informed, men receiving a medication for prostate gland enlargement reported a $28.3 \%$ increase in sexual dysfunction when informed it was a side effect. ${ }^{2}$ Similarly, patients receiving treatment for unstable angina pectoris informed of possible gastrointestinal side effects were six times more likely than patients who had not been informed to stop treatment due to these side effects. ${ }^{4}$

A recent review assessed 27 studies that attempted to inform patients about side effects without increasing their likelihood and found that the most effective intervention was to refrain from disclosing side effects. ${ }^{5}$ But withholding side effect information from patients is problematic. Patients need to be informed of possible side effects so they can make educated decisions about treatment and know when to seek medical help. Withholding side effect information may also undermine trust in patient-provider relationships, thereby worsening health outcomes over time. This puts healthcare providers in a difficult position. How can providers fully inform patients while upholding their oath to do no unnecessary harm?

\section{RETHINKING SIDE EFFECTS}

An emerging approach attempts to achieve both goals: truthfully describe certain minor side effects as a sign the treatment is active and working in the body. ${ }^{6-8}$ This approach is more nuanced than simply deciding which side effects to disclose to patients. Instead, it focuses on instilling adaptive mindsets about the meaning of side effects while still informing patients about them.

To understand this approach, it is first helpful to think through the mindset patients typically have about side effects. At best, patients may assume that side effects are unfortunate or harmful byproducts of treatment. At worst, patients may assume that side effects are a sign that the treatment is not working, that their body is particularly sensitive to medication or that their own condition is treatment resistant.

These negative assumptions overlook a more encouraging truth about side effects: for many conditions and treatments, side effects can indicate that the treatment is active and working in the body. ${ }^{8-10}$ Take vaccinations for example: vaccinations work by activating the body's immune response, which helps the body remember a particular virus in case it ever invades the body again. As a result, most side effects from vaccinations are a signal that the body is starting to build up the immune system so that it can tolerate the virus in case of future infection. ${ }^{11} 12$ Similarly, during oral 
immunotherapy for food allergies, patients may have mild side effects (eg, itchy mouth, nausea) when consuming their doses. However, patients may not realise that these mild side effects can indicate that the body is building allergen desensitisation. ${ }^{8}$ Another good example is antibiotics: when antibiotics effectively kill harmful bacteria in the body, they also frequently kill helpful bacteria in the intestine, resulting in unpleasant, but usually not dangerous, side effects, such as diarrhoea. ${ }^{13}$ These side effects can thus signal that the antibiotics are working. Similarly, chemotherapy works by killing fast-growing cancer cells, but can also kill fast-growing healthy cells, such as hair follicles and cells in the digestive track. ${ }^{14}$ This can lead to common side effects, such as hair loss and nausea, that are emotionally intense but also signs that the treatment is active in the body.

The ways providers communicate about side effects play an important role in shaping patients' mindsets about them. ${ }^{15} 16$ In many cases, patients may view side effects as wholly negative, even when there is evidence to support otherwise. Even well-intentioned efforts to inform patients and empathise with them about side effects may inadvertently serve to instil and reinforce the mindset that side effects are wholly negative. By being mindful when describing side effects, providers can help patients rethink their meaning. Describing minor, nonlife-threatening side effects as a sign the treatment is working can instil the mindset that, although they may be uncomfortable, these side effects indicate treatment progress.

\section{STATE OF THE SCIENCE}

To date, three studies have empirically tested the approach of describing side effects as a sign that treatment is working (table 1). Results from these studies suggest that this approach significantly improves patient's experience during treatment. Compared with control groups given a standard, empathetic message about side effects, patients who were informed that side effects are a sign treatment is working were less anxious about side effects $^{8}$ and rated side effects as less threatening ${ }^{6}$ and less intense. ${ }^{7}$ Reducing threat, worry and intensity of side effects are powerful ways to improve overall treatment experience.

There is also evidence that this approach can reduce the number of questions providers receive about side effects. One longitudinal randomised controlled trial examined the influence of mindset about side effects on children/adolescents undergoing oral immunotherapy for peanut allergies. This study found that during the 6-month treatment, describing side effects as a sign treatment was working reduced the rate at which patients contacted providers with concerns about side effects. ${ }^{8}$ This outcome is especially encouraging given the many demands on providers' time and the costs associated with answering patients' questions outside of office visits.
This approach may also increase treatment efficacy. The study of children/adolescents undergoing oral immunotherapy found that patients informed that side effects were a sign the treatment was working had greater increases in a biomarker of allergic tolerance from pretreatment to post-treatment (peanut-specific blood IgG4) ${ }^{8}$ Likewise, Fernandez et al found that, for participants informed that side effects were a sign an analgesic was working, experiencing side effects was associated with increased analgesic efficacy, with these participants reporting a greater increase in pain reduction. ${ }^{7}$ These findings align with other research demonstrating that the presence of side effects can increase a treatment's effectiveness, in part by strengthening beliefs that the treatment is working. ${ }^{9}$ Research on fear avoidance of bodily symptoms also supports these findings: changing patients' perceptions of side effects' threateningness can impact their occurrence, intensity and unpleasantness. ${ }^{17}$

How does this approach influence overall side effect occurrence? Two of the studies found that groups that were informed that side effects were a sign the treatment was working experienced a similar number of side effects as control groups ${ }^{67}$ Yet these participants rated their side effects as less threatening and intense, suggesting that it is possible to improve the experience of side effects without reducing their occurrence. Another study found that this approach reduced side effects at the highest treatment doses (there was no difference between groups at low doses $)^{8}$ (table 1). Future studies should continue to assess how this approach influences side effect occurrence and reporting.

Importantly, evidence also suggests that participants preferred this approach. At the end of their study, Fernandez et al exposed all participants to both a standard side effects description and the description of side effects as a sign the treatment is working. Overall, $65 \%$ of participants preferred the latter. ${ }^{7}$ This suggests that, when given an informed choice, most people prefer to have side effects explained as an indication of treatment efficacy.

\section{ETHICALLY APPLYING THIS APPROACH Key considerations}

This approach to discussing side effects should not be applied universally. Several key issues must be considered in order to achieve the ultimate goals of informing the patient and doing no harm. Most importantly, the information about side effects should be true and supported by mechanistic evidence suggesting that the side effects mean the treatment is active and working in the body. Providers should never misinform patients about a particular treatment or associated side effect. Fortunately, there are many cases in which these links are well documented, as previously described in the cases of vaccinations, immunotherapy, antibiotics and chemotherapy. Future research may continue to shed light on cases where side effects are linked with treatment efficacy. 
Table 1 Empirical results of describing side effects as a sign treatment is active and working

\begin{tabular}{|c|c|c|c|c|c|}
\hline \multirow[b]{2}{*}{$\begin{array}{l}\text { Study and } \\
\text { population* }\end{array}$} & \multirow{2}{*}{$\begin{array}{l}\text { Language used } \\
\text { to describe side } \\
\text { effects as a sign } \\
\text { the treatment is } \\
\text { working* }^{\star}\end{array}$} & \multicolumn{4}{|l|}{ Results† } \\
\hline & & Side effects & $\begin{array}{l}\text { Treatment } \\
\text { experience }\end{array}$ & Adherence & $\begin{array}{l}\text { Treatment } \\
\text { outcomes }\end{array}$ \\
\hline $\begin{array}{l}\text { Fernandez et al } \\
66 \text { healthy male } \\
\text { volunteers receiving } \\
\text { an analgesic } \\
\text { (diclofenac) before } \\
\text { exposure to pain }\end{array}$ & $\begin{array}{l}\text { 'If you do experience } \\
\text { a side effect, you } \\
\text { might take this as a } \\
\text { a reminder that the } \\
\text { analgesic medication } \\
\text { is active in your } \\
\text { body...this is a signal } \\
\text { that the drug is } \\
\text { working'. } \\
\text { Communicated via } \\
\text { video }\end{array}$ & $\begin{array}{l}\text { No difference in } \\
\text { occurrence } \\
\text { More likely } \\
\text { to perceive } \\
\text { symptoms as } \\
\text { caused by the } \\
\text { medication }\end{array}$ & $\begin{array}{l}\text { Side effects } \\
\text { experienced as less } \\
\text { intense }\end{array}$ & N/A & $\begin{array}{l}\text { Positive correlation } \\
\text { between side effects } \\
\text { and reported pain } \\
\text { reduction from } \\
\text { treatment }\end{array}$ \\
\hline $\begin{array}{l}\text { Wilhelm et } \text { al }^{6} \\
80 \text { healthy male } \\
\text { participants between } \\
\text { ages } 18 \text { and } 35 \\
\text { given a hypertensive } \\
\text { medication } \\
\text { (metoprolol) }\end{array}$ & $\begin{array}{l}\text { 'Dizziness is a sign } \\
\text { that the drug is } \\
\text { starting to work. } \\
\text { If you become } \\
\text { dizzy after taking } \\
\text { the medication, it } \\
\text { means that your } \\
\text { body is responding } \\
\text { to the beta-blocker } \\
\text { particularly well'. } \\
\text { Communicated } \\
\text { verbally }\end{array}$ & No difference & $\begin{array}{l}\text { Side effects } \\
\text { experienced as } \\
\text { less threatening } \\
\text { and less likely to } \\
\text { view side effects as } \\
\text { an adverse effect of } \\
\text { medication }\end{array}$ & N/A & N/A \\
\hline
\end{tabular}

*In all three studies, participants were randomised to either be informed that side effects were a sign the treatment was active/working or to receive a standard description of side effects. The standard description informed patients about potential side effects and provided sympathetic statements like 'we will do our best to ensure your comfort'.

†Results depict the effect of describing side effects as a sign the treatment is active/working as compared with the condition that received the standard description.

Many drugs and treatments have a range of side effects, some of which are severe and require medical attention and some of which are more minor. This approach should only be applied to minor, non-life-threatening symptoms that may be uncomfortable, but are likely to be resolved without medical attention (eg, mild headaches, dizziness or nausea). Providers should never minimise harmful or life-threatening side effects, as they are an important factor in making the decision to undergo treatment. It is critical that providers distinguish which side effects necessitate medical action, as in previous clinical research on this approach: the longitudinal study of this strategy in oral immunotherapy clearly distinguished between minor, non-life-threatening side effects that signalled treatment efficacy and the few, rare side effects that required medical intervention. ${ }^{8}$ Only after such a distinction can providers safely describe minor, non-lifethreatening side effects as a sign treatment is working. This strategy can help patients understand which side effects are serious while changing the meaning of common, nonserious side effects that frequently interfere with adherence to safe and effective treatments. Which side effects can be appropriately described as signals of treatment efficacy will vary by condition, treatment and patient. As with other health messaging and treatments themselves, providers and care teams must decide on a case-by-case basis whether side effects can be described as a sign the treatment is working. 
A final, more nuanced, concern is to consider how patients may respond to this mindset in the cases when they do not experience symptoms. If patients are told that side effects mean the treatment is working, they may interpret a lack of side effects as a sign that the treatment is not working. Even while describing side effects as a sign treatment is working, providers can be clear that a lack of side effects is not indicative of treatment failure. Since the typical patient's mindset may be that 'no side effects is good news', patients will likely recognise a lack of symptoms as a sign the treatment is going well. This is supported by the research on this approach. In the clinical, longitudinal study, patients who remained side effect-free believed that treatment was working just as well for them as patients who experienced side effects. ${ }^{8}$ This suggests that even when side effects are given a positive meaning, a lack of side effects is not necessarily viewed as problematic or undesirable.

\section{Future research and fertile ground}

Changing patients' mindsets so that they view minor side effects as signs that the treatment is working, rather than worrisome indicators that the treatment is ineffective or harmful, can improve patients' experience and outcomes while still keeping patients informed. Evidence in favour of this approach for certain symptoms and conditions is promising, but in its early stages, and more research is needed to effectively understand and leverage it.

To support this approach, further efforts are needed to understand the complex relationship between side effects and drug mechanisms. As part of drug trials, drug manufacturers should be asked to not only to measure and document the potential side effects associated with treatments, but also to describe how the side effects may relate to the mechanisms of treatment efficacy.

Research is also needed on best practices for communicating information about the meaning, probability and frequency of side effects. Other strategies have been suggested for communicating side effect frequency, ${ }^{18}$ and future research is needed to understand how describing side effects as signs of treatment efficacy interacts with other messaging strategies aimed to reduce side effects. For example, several studies have found that positive framing may reduce side effects. Positive framing refers to sharing information on number of people who do not experience side effects as opposed to sharing the number of people who do (eg, ' $95 \%$ of patients do not experience side effects of headache or dizziness' vs ' $5 \%$ of patients experience headache or dizziness'). ${ }^{19}$ Future studies might test a strategy of emphasising the number of people who do not experience side effects and highlighting that, in the unlikely event a patient does experience side effects, these side effects are a sign the treatment is working. These studies could help us understand whether a multitiered message is more effective than using either strategy alone.

The studies reviewed here communicated the message that side effects signal treatment efficacy in a number of different ways, including a brief face-to-face interaction, a video message and an intensive 6-month intervention. Future research should explore how different vehicles for communicating information regarding side effects, such as government websites, advertising and the media, influence patients' mindsets about side effects for better or for worse. $^{20}$

This approach provides fertile ground for exploring other ways in which this mindset may be useful. For example, explaining side effects as a sign that treatment is working may be particularly helpful for certain treatments, such as antidepressants, where side effects may precede healing by weeks or months. Describing side effects as a sign that these treatments are working may give patients hope and motivation to persevere until treatment takes effect. Relatedly, this approach may help when necessary medications provide little symptomatic relief, such as in hypertension. ${ }^{21}$ Since hypertension is often asymptomatic, side effects may make patients feel worse than they did without medication. In these cases, reassuring patients that minor side effects are a positive sign that treatment is working may help patients recognise medications' benefits. Indeed, minor side effects can produce anxiety and worry that is disproportionate to patients' physical symptoms. This is one reason patients often come to the doctor's office primarily seeking reassurance. ${ }^{22}$ By anticipating and addressing patients' (conscious or unconscious) fears that side effects indicate the treatment is not going well, this approach can reduce treatment-related anxiety ${ }^{68}$ and may motivate patients to stick with treatment despite side effects. ${ }^{10}$

This approach may also be useful for shaping patient's mindsets about symptoms that do not require medical treatment, such as those associated with colds and other viruses. While patients might not be aware of this, uncomfortable symptoms can be a natural part of the healing process. ${ }^{23}$ Fevers and associated achiness and chills are a sign the body is fighting infection. ${ }^{24}$ Likewise, wound inflammation is indicative of a healing response in which enzymes and histamines are released. ${ }^{25}$ Informing patients that certain minor symptoms are part of the body's natural healing processes may reduce demands for unnecessary medications, such as antibiotics for colds, while also reassuring patients when these symptoms are not dangerous. While these areas represent particularly viable options for additional research, future studies can help us broadly understand what patients, situations and treatments this approach is most beneficial for.

Leveraging mindset: a useful tool for physicians more broadly How to disclose side effects without increasing their likelihood has been a problem for decades. Yet relatively little progress has been made addressing it. Describing minor side effects as a sign the treatment is active and working is a promising strategy for more fully informing patients about potential side effects without causing unnecessary harm. Importantly, this potential solution highlights how providers' ability to shape patients' mindsets during 
treatment can be fruitfully applied to improve healthcare. Rethinking how providers inform patients about side effects is just one of the many possible opportunities to instil beneficial mindsets in the clinical encounter.

Correction notice This article has been corrected since it was published. Ted Kaptchuk has been acknowledged in the Acknowledgements section.

Twitter Kari A Leibowitz @karismatically, Lauren C Howe @howelaurenc and Alia J Crum @AliaCrum

Acknowledgements The authors would like to thank Ted Kaptchuk, Maggie Perry, Isaac Handley-Miner, Lauren Heathcote, Brad Turnwald and Larry Kwan for their comments on this manuscript.

Contributors KAL, LCH and AJC are experts in health psychology and have conducted research testing the approach of describing side effects as positive signals in clinical practice. All authors contributed to the concepts and structure of this manuscript. AJC is the guarantor.

Funding The authors have not declared a specific grant for this research from any funding agency in the public, commercial or not-for-profit sectors.

Competing interests None declared.

Patient consent for publication Not required.

Provenance and peer review Not commissioned; externally peer reviewed.

Open access This is an open access article distributed in accordance with the Creative Commons Attribution Non Commercial (CC BY-NC 4.0) license, which permits others to distribute, remix, adapt, build upon this work non-commercially, and license their derivative works on different terms, provided the original work is properly cited, appropriate credit is given, any changes made indicated, and the use is non-commercial. See: http://creativecommons.org/licenses/by-nc/4.0/.

ORCID iD

Kari A Leibowitz http://orcid.org/0000-0001-7494-7270

\section{REFERENCES}

1 Petrie KJ, Rief W. Psychobiological mechanisms of placebo and nocebo effects: pathways to improve treatments and reduce side effects. Annu Rev Psychol 2019;70:1-27.

2 Mondaini N, Gontero P, Giubilei G, et al. Finasteride $5 \mathrm{Mg}$ and sexual side effects: how many of these are related to a nocebo phenomenon? J Sex Med 2007.

3 Colloca L, Finniss D. Nocebo effects, patient-clinician communication, and therapeutic outcomes. JAMA 2012;307:567-8.

4 Myers MG, Cairns JA, Singer J. The consent form as a possible cause of side effects. Clin Pharmacol Ther 1987;42:250-3.

5 Webster RK, Rubin GJ. Influencing side-effects to medicinal treatments: a systematic review of brief psychological interventions. Front. Psychiatry 2019;9.
6 Wilhelm M, Rief W, Doering BK. Decreasing the burden of side effects through positive message framing: an experimental proof-ofconcept study. Int J Behav Med 2018;25:381-9.

7 Fernandez A, Kirsch I, Noël L, et al. A test of positive suggestions about side effects as a way of enhancing the analgesic response to NSAIDs. PLoS One 2019;14:e0209851-16.

8 Howe LC, Leibowitz KA, Perry MA, et al. Changing patient Mindsets about Non-Life-Threatening symptoms during oral immunotherapy: a randomized clinical trial. J Allergy Clin Immunol 2019;7:1550-9.

9 Berna C, Kirsch I, Zion SR, et al. Side effects can enhance treatment response through expectancy effects: an experimental analgesic randomized controlled trial. Pain 2017;158:1014-20.

10 Rees S. No one scans you and says 'you're alright now' : the experience of embodied risk for young women living with a history of breast cancer. Health Risk Soc 2018;20:312-24 https://doi.org/

11 Vaccine Side Effects | Vaccines [Internet]. Available: https://www. vaccines.gov/basics/safety/side_effects [Accessed cited 2020 Oct 29].

12 CDC, Ncird. Understanding How Vaccines Work The Immune System-The Body's Defense Against Infection [Internet]. Available: https://www.niaid.nih.gov/research/how- [Accessed cited 2020 Oct 30].

13 Varughese CA, Vakil NH, Phillips KM. Antibiotic-associated diarrhea: A refresher on causes and possible prevention with probiotics - Continuing education article. J Pharm Pract 2013;26:476-82.

14 The American Cancer Society medical and editorial team. Chemotherapy: side effects [Internet], 2016. Available: https://www. cancer.org/treatment/treatments-and-side-effects/treatment-types/ chemotherapy/chemotherapy-side-effects.html

15 Crum AJ, Leibowitz KA, Verghese A. Making mindsets matter. $\mathrm{Br}$ Med J 2017;356:674-8.

16 Crum A, Zuckerman B. Changing Mindsets to enhance treatment effectiveness. JAMA 2017;317:2063.

17 Vlaeyen JWS, Crombez G, Linton SJ. The fear-avoidance model of pain. Pain 2016;157:1588-9.

18 Bingel U, Placebo Competence Team. Avoiding nocebo effects to optimize treatment outcome. JAMA 2014;312:693.

19 Barnes K, Faasse K, Geers AL, et al. Can positive framing reduce nocebo side effects? current evidence and recommendation for future research. Front Pharmacol 2019;10.

20 Faasse K, Porsius JT, Faasse J, et al. Bad news: the influence of news coverage and Google searches on Gardasil adverse event reporting. Vaccine 2017;35:6872-8.

21 Osterberg L, Blaschke T. Drug therapy: adherence to medication. $N$ Engl J Med 2005.

22 Van de Kar A, Knottnerus A, Meertens R, et al. Why do patients consult the general practitioner? determinants of their decision. $\mathrm{Br} \mathrm{J}$ Gen Pract 1992;42:313-6.

23 Crocetti M, Moghbeli N, Serwint J. Fever phobia revisited: have parental misconceptions about fever changed in 20 years? Pediatrics 2001;107:1241-6.

24 Blatteis CM. Fever: pathological or physiological, injurious or beneficial? J Therm Biol 2003;28:1-13.

25 Diegelmann RF, Evans MC. Wound healing: an overview of acute, fibrotic and delayed healing. Front Biosci 2004;9:283. 